\title{
La llegada de Radio Moscú a España: cultura y comunismo en la crisis social española (1932-1936)
}

Laila Natalí Pecheny

Facultad de Ciencias Sociales- Universidad

de Buenos Aires, Argentina

\section{Resumen}

El objetivo de este artículo es describir y problematizar las formas de intervención y los sentidos promovidos por Radio Moscú en castellano durante su emergencia en España (1932-1936). La hipótesis sostiene que aunque la emisora de la Unión Soviética (URSs) fue creada para intervenir políticamente en otros países, logró introducirse en la particular coyuntura de la Segunda República, principalmente a partir de una programación cultural. La profundización de la politización de las emisiones únicamente pudo darse de forma interrumpida con el aumento generalizado de la conflictividad social en diciembre de 1933, octubre de 1934 y enero-febrero de 1936. A partir de esto, se concluyó que la llegada de Radio Moscú a España fue la resultante de la articulación de un proceso social donde intervinieron el sistema de medios ya presente con formas de recepción y funciones sociales definidas, las crisis sociales de la

Palabras clave:

Radiodifusión, onda corta, Guerra Civil Española, materialismo cultural, Unión Soviética 
transición republicana, la situación interna del Partido Comunista Español (PCE), las políticas del Estado Soviético destinadas a romper el aislamiento, y la nueva política frente populista de la Internacional Comunista (IC). Se trabajó desde un abordaje cualitativo de artículos de publicaciones como Heraldo de Madrid, La Voz, Luz, La Libertad, Pensamiento Alavés, El Siglo Futuro, Catalunya Social, La Veu de Catalunya, El Diluvio, ABC, El Socialista, Mundo Obrero, La Nación, Gracia y Justicia, Ondas, Letras, Blanco y Negro, Crónica y Orbe, relevados de la Hemeroteca digital de la Biblioteca Nacional de España y de la Biblioteca Virtual de Prensa Histórica.

\section{Abstract}

\section{The arrival of Radio Moscow in Spain: culture and communism in the Spanish social crisis} (1932-1936)

The aim of this article is to describe and problematize the forms of intervention and meanings promoted by Radio Moscow in Spanish during its emergence in Spain (1932-1936). The hypothesis poses that although the broadcasting station of the Soviet Union (USSR) was created to intervene politically in other countries, it managed to enter into the particular situation of the Second Republic, mainly through cultural programming. The deepening of the politicization of the broadcasts could only occur on a disrupted basis with the generalized increase in the social conflict in December 1933, October 1934 and January-February 1936. Based on the previously mentioned, it was concluded that the arrival of Radio Moscow to Spain was the result of the articulation of a social process where the already present broadcasting system intervened with forms of reception and defined social functions, the social crises of the republican transition, the internal situation of the Spanish
Keywords:

Broadcasting, short wave, Spanish Civil War, cultural materialism, Soviet Union 
Communist Party (PCE), the policies of the Soviet State aimed at breaking its isolation, and the new popular front policy of the Communist International (CI). We worked from a qualitative approach of articles from publications such as Heraldo de Madrid, La Voz, Luz, La Libertad, Pensamiento Alavés, El Siglo Futuro, Catalunya Social, La Veu de Catalunya, El Diluvio, ABC, El Socialista, Mundo Obrero, La Nación, Gracia y Justicia, Ondas, Letras, Blanco y Negro, Crónica y Orbe, obtained from the digital newspaper archives of the National Library of Spain and the Virtual Library of Historical Press.

\section{Resumo}

\section{A chegada da Rádio Moscou à Espanha: cultura e comunismo na crise social espanhola (1932-1936)}

O objetivo deste artigo é descrever e problematizar as formas de intervenção e os sentidos promovidos pela Rádio Moscou em espanhol durante seu surgimento na Espanha (1932-1936). A hipótese sustenta que embora a estação da União Soviética (URSs) tenha sido criada para intervir politicamente em outros países, ela conseguiu introduzir-se na situação particular da Segunda República, principalmente por meio da programação cultural. O aprofundamento da politizaçấo das emissoras só poderia ocorrer de forma interrompida com o aumento generalizado da inquietação social em dezembro de 1933 , outubro de 1934 e janeiro-fevereiro de 1936 . A partir disso, concluiu-se que a chegada da Rádio de Moscou para a Espanha foi o resultado da articulação de um processo social onde interveio o sistema de mídias já presente com formas de recepção e funçóes sociais já definidas, as crises sociais da transição republicana, a situação interna do Partido Comunista Espanhol (PCE), as políticas do estado soviético para quebrar o isolamento, e a nova política «frente populista» da Internacional Comunista
Palavras chave:

Radiodifusão, onda curta, Guerra Civil Espanhola, materialismo cultural, União Soviética 
(cI). O trabalho foi feito a partir de uma abordagem qualitativa de artigos de publicaçóes como Heraldo de Madrid, La Voz, Luz, La Libertad, Pensamiento Alavés, El Siglo Futuro, Catalunya Social, La Veu de Catalunya, El Diluvio, ABC, El Socialista, Mundo Obrero, La Nación, Gracia y Justicia, Ondas, Letras, Blanco y Negro, Crónica y Orbe, arquivadas na Hemeroteca digital da Biblioteca Nacional da Espanha e na Biblioteca Virtual de Imprensa Histórica.

\section{Introducción}

A partir de 1929, el Comité de Radio de Toda la Unión del Consejo de Comisarios del Pueblo de la Unión Soviética comenzó a transmitir internacionalmente en «onda corta» (Glazov, 20I7). ${ }^{1}$ La creación de Radio Moscú fue impulsada por el Estado soviético como parte de las políticas destinadas a quebrar el aislamiento tanto respecto de los países capitalistas occidentales como de los regímenes de derecha que rodeaban a la Unión. ${ }^{2}$ Esta actividad fue controlada y supervisada en detalle tanto por la Comisaría del
Pueblo de Asuntos Exteriores como por el Glavlit (Administración Principal para la Salvaguarda de los Secretos de Estado en la Prensa) que se encargaba de la censura. Aunque no estuviesen formalmente relacionados con la emisora, en los hechos tanto la Internacional Comunista (IC) como el Departamento de Cultura y Educación del Comité Central del Partido Comunista de la Unión Soviética (pCus) tuvieron influencia en decisiones importantes como la selección de personal o la elección de contenidos (Glazov, idem). En este período emergente, el

1 Un rango de frecuencia de señales electromagnéticas con capacidad de alcanzar largas distancias, o incluso dar la vuelta al mundo.

2 EI rechazo a la URSS se venía manifestando desde 1918 con la "intervención aliada" (EEUU, Inglaterra y Francia principalmente apoyaron a los rusos blancos durante la guerra civil) y con la invasión japonesa en el lejano oriente. Con la consolidación de la URSS las democracias occidentales continuaron negando el reconocimiento del nuevo régimen. Para la década del '30 la URSS se vio amenazada desde ambos flancos por la ocupación japonesa de Dongbei Pingyuan (Manchuria) y por el ascenso de Adolf Hitler en Alemania que ponía en tensión el lado occidental. La situación empeoraba por la existencia de aliados totalitarios como Italia y Portugal y por la expansión de movimientos fascistas en países como Finlandia, Rumania y Lituania. 
sector de idiomas extranjeros transmitió al mundo informaciones tomadas directamente desde la agencia de noticias del Estado, la TASs (Agencia Telegráfica de la Unión Soviética), haciendo que en un primer momento los programas se asemejasen a un periódico hablado.

El inglés, el francés y el alemán fueron los primeros idiomas extranjeros con los que la radio soviética se dirigió al mundo. Tres años más tarde, en 1932 empezaron a producirse emisiones regulares en castellano. Al inicio, las emisiones en español fueron desordenadas y desprolijas. Se encontraban prácticamente a cargo de una única persona y sin editor responsable, lo que muchas veces dificultaba la realización de la actividad en tiempo y forma. Aun así, Luis Cecchini fue el encargado de realizar diariamente las transmisiones nocturnas, asumiendo las tareas de locutor, redactor, editor, traductor, mecanógrafo y reportero. ${ }^{3}$

La llegada de Radio Moscú a España (1932-1936) fue el resultado de la articulación de un proceso social dinámico donde intervinieron las formas de recepción y el campo comunicacional ya existentes, las diferentes políticas y pujas internas del gobierno español y soviético, las disputas al interior de la IC, la situación interna del Partido Comunista de España (PCE) y las crisis sociales inherentes a la transición republicana. Aunque la emisora de la Unión Soviética (URSs) fue creada para intervenir políticamente en otros países de manera propagandística, ${ }^{4}$ logró introducirse en la particular coyuntura de la Segunda República, principalmente a partir de una programación cultural. Radio Moscú únicamente pudo profundizar la politización de sus emisiones en diciembre de 1933, octubre de 1934 y enero y febrero de 1936, con el ahondamiento de las propias tensiones del conflicto español.

La radio como medio hegemónico de entreguerras en la península ibérica ya ha sido trabajada por diversos autores. Javier Cervera Gil (1998) y Daniel Arasa (2015) realizaron un gran aporte al estudiar las emisoras como parte del campo de batalla comunicacional durante la Guerra Civil. Abordando el mismo período, Alejandro Pizarroso Quintero (200I) ha contribuido a la investigación sobre la intervención extranjera desde el punto de vista propagandístico. De igual modo, Miguel Vázquez Liñán (2003) identificó los canales, mensajes y técnicas de las comunicaciones soviéticas en España. Sin embargo, aún queda por indagar en

3 El ex ferroviario del Comité Central del Partido Comunista de la Argentina se había exiliado en la URSS luego de ser perseguido políticamente durante el Golpe de Estado de 1930 en su país de origen.

4 Se entiende por "propaganda" a las políticas difusionistas destinadas a divulgar las ideas y políticas del partido (Lenin, 1902) 
mayor profundidad las formas de radiodifusión soviética en español durante toda la década de 1930.

El presente trabajo es un primer abordaje que forma parte de un proyecto de investigación mayor que busca estudiar el fenómeno de la emisora de Moscú en España durante sus primeros años. Se considera relevante investigar el caso desde de la Historia de los Medios ya que puede servir como un antecedente para el estudio de las políticas comunicacionales. A su vez, también se pretende aportar al desarrollo de diversas líneas de investigación referentes a la propia historia política de España, de la Unión Soviética y de la cultura comunista.

Desde el marco teórico del materialismo cultural se comprende a los medios como partícipes del propio proceso de producción desde su dimensión material y simbólica. De modo que, entendiendo al igual que Raymond Williams (1958) que la cultura siempre es tradicional y creativa a la vez, puede pensarse que los cambios experimentados durante la crisis social habilitaron una apertura para la producción de nuevas significaciones. Considerando que la experiencia cultural también tiene una dimensión material que abarca a los medios de comunicación (Spigel, 1992), se puede afirmar que estas luchas hegemónicas también se desarrollaron en el campo mediático. Fue este escenario el que habilitó que la emisora de Moscú pudiese montar toda una serie de acciones para su emergencia durante la nueva república.

Teniendo en cuenta que se trabajó con un medio no inscriptivo y en un período prebélico del cual hay muy poca conservación de materiales, se definió un abordaje cualitativo de las noticias y grillas de programación publicadas en periódicos y revistas relevantes de la época relevados de la Hemeroteca digital de la Biblioteca Nacional de España y de la Biblioteca Virtual de Prensa Histórica. Se consideró que la importancia de ciertas emisiones de Radio Moscú en España queda demostrada al haber sido registradas por los principales periódicos y revistas de la época. Atendiendo a la enorme cantidad de mediaciones que se presentan en el objeto de estudio, se practicó una mirada oblicua sobre las fuentes (Burke, 1982).

Interesa el abordaje de esta problematización ya que se entiende que fue una de las primeras experiencias en comunicación política internacional en castellano desde el país de los soviets destinadas a intervenir en una sociedad extranjera. A partir de ello se pretende profundizar en la relación entre los medios de comunicación y las políticas internacionales en las disputas hegemónicas de la crisis social española que tiene su fase más trágica en el estallido de la Guerra Civil.

\section{Emergencia en España}

La emergencia de Radio Moscú en España se produjo en un período transicional 
donde el nuevo orden republicano aún no había resuelto las contradicciones sociales inherentes a los sistemas políticos y económicos de antaño. La propia república estuvo conformada por un bloque sociopolítico amplio con pujas internas entre liberales, centristas y socialistas, que a su vez también se vio tensionado por disputas con comunistas, anarquistas y las izquierdas republicanas. Esta situación se complicaba con la continuidad del problema de la miseria generalizada producto de la sobreexplotación de los sectores obreros y especialmente de los campesinos que se encontraban trabajando en condiciones semifeudales. Con la proclamación de la república, toda una serie de reclamos sindicales reprimidos se manifestaron plenamente en las calles en huelgas y movilizaciones. A esto se le sumó el descontento de las derechas ante una Constitución que proclamaba las autonomías territoriales y la ruptura con la Iglesia, y el empuje de parte del republicanismo de las reformas agraria, militar y educativa. Estas fuerzas políticas intentaron recuperar sus posiciones de poder a partir de levantamientos pero también presentando fuertes coaliciones en las elecciones democráticas. Así, el período abordado se caracterizó por tener un contexto de fuertes luchas hegemónicas. La intervención del Estado soviético en España debió superar una barrera impuesta de manera involuntaria por las propias políticas del PCE. Este contexto social de crisis se expresó en disputas al interior de la sección local del comunismo. Para la Ic la vieja dirección española frenaba el desarrollo del partido al continuar promoviendo consignas contrarias a la instauración de la Segunda República que impedían dialogar con las masas. ${ }^{5}$ En I93I el PCE tenía menos de 800 militantes y una escasa organización (Cruz, 1987), lo cual era insuficiente para promover la difusión de material propagandístico soviético o hacer circular de forma masiva los periódicos. ${ }^{6}$ Frente a esto, el comunismo internacional nucleado en la organización conocida como Komintern o Internacional Comunista (IC), intervino directamente en la organización del PCE expulsando a los antiguos líderes

5 La proclamación de la Segunda República fue un proceso desordenado. Las movilizaciones populares se impusieron el 14 de abril por sobre los intentos de realizar una transición pactada con el rey. Para la Komintern, las políticas de la antigua dirección habían quedado atrasadas respecto al nuevo escenario. El Comité Central del PCE afirma en "Historia del PCE" (1960) que durante el IV Congreso del PCE se discutió una nueva política donde lo central no era movilizar a las masas para la caída de la dictadura con el rey, sino de desarrollar hasta el fin la revolución democrático-burguesa.

6 En los comienzos de la Segunda República, el PCE tenía un número muy bajo de militantes. Según Rafael Cruz (1987) aunque las afiliaciones no eran menores a 120, tampoco llegaban a ser más de 800 . 
y reemplazándolos por nuevos cuadros dirigentes. ${ }^{7}$ Por todo esto, la decisión de empezar con las transmisiones en castellano fue la forma que encontró el Estado soviético de sortear estos inconvenientes y empezar a actuar en Espańa sin tener que depender del comunismo español que aún era débil.

Una vez intervenido, desde su órgano oficial Mundo Obrero, el PCE contribuyó a difundir los programas de Radio Moscú entre sus lectores y afiliados. Además, el propio Estado Soviético promovió el desarrollo de organizaciones más amplias que se dedicaron a construir una audiencia para la emisora. A su vez, se precisó del apoyo de organizaciones prosoviética como Socorro Rojo Internacional ${ }^{8} \mathrm{y}$ asociaciones antifascistas diversas que impulsaron desde España la creación de una audiencia para la radio soviética. La Asociación de Amigos de la Unión Soviética (AUS) ${ }^{9}$ creada en I933, ayudó a resolver los problemas de sintonización y la escasez de aparatos receptores de onda corta publicando estas informaciones en su periódico Rusia de Hoy (Vázquez Liñán, 2003). Esta sociedad se dedicó a organizar grupos de aficionados y se encargó de tomar nota de los aparatos que podían sintonizar la radio de Moscú. Además buscó diferentes maneras para conseguir receptores y organizó escuchas grupales de la radio soviética.

Frente al comienzo de las transmisiones de Radio Moscú en castellano se condensaron dos concepciones diferenciadas. Mientras por un lado republicanos, socialistas, comunistas y radioaficionados consideraron a la emisora de Moscú en clave modernizadora, por el otro, conservadores, nacionalistas y organizaciones de derecha la entendieron como parte de una progresiva sovietización de España.

Desde la primera perspectiva, Radio Moscú fue considerada como parte de

7 José Bullejos, Gabriel León Trilla, Etelvino Vega Martínez y Manuel Adame que habían dirigido al partido durante la clandestinidad, fueron expulsados del Comité Central del PCE. José Díaz, Dolores Ibaurrí, Vicente Uribe y Antonio Mije fueron los cuadros escogidos por la IC para dirigir la sección española y aplicar un cambio de programa.

8 La organización Socorro Rojo Internacional había comenzado a operar en España en 1923 de manera clandestina para ayudar a los presos políticos comunistas de la dictadura de Primo de Rivera. En un primer momento su órgano oficial era Combate, siendo reemplazado luego por Amnistía. Fue una organización amplia que buscó nuclear a quienes teniendo ideas liberales y humanistas aspirasen a nuevos horizontes de civilización y libertad (Vázquez Liñán, 2003).

9 La Asociación de Amigos de la Unión Soviética (AUS) fue creada en febrero de 1933 por importantes intelectuales españoles como Diego Hidalgo, Pedro de Répide, Ortega y Gasset, Eduardo Barriobero, Gregorio Marañón y Luis Jiménez de Asúa, entre otros. 
una política soviética dedicada a esparcir la cultura y la modernización. ${ }^{10}$ Periódicos generalistas republicanos como Heraldo de Madrid, ${ }^{11}$ La Voz $^{12}$ o El Luchador ${ }^{13}$ de Alicante; prensa partidaria como $E l$ Socialista ${ }^{14}$ o Mundo Obrero ${ }^{15}$; y revistas especializadas como Ondas ${ }^{16}$ y Orbe $^{17}$ fueron algunas de las publicaciones que difundieron esta perspectiva. Estos medios sirvieron en gran medida para difundir la programación de la emisora, visibilizándola y dándole una entidad entre los medios de comunicación presentes en España.

Dentro de este punto de vista, el caso de Radio Moscú era utilizado para proponer soluciones a sus propias problemáticas. Comparaban los alcances de la radio soviética con el estancamiento de la radiodifusión española que aún no había logrado establecer una Red Nacional de Radiodifusión que llegase a todo el territorio. ${ }^{18}$ Se planteaba que al igual que había sucedido en la urss,

10 "La 'radio' como medio eficaz de instrucción en Rusia" (29 de agosto de 1932) en La Voz (Madrid): Año XIII N³.642, p.06.

11 El Heraldo de Madrid fue uno de los principales periódicos de España con un alto número de tiradas. Se editó en la capital española entre 1890 y 1939. Durante la Segunda República estaba dirigido por Francisco Villanueva. Fue abiertamente republicano. Con el fin de la República fue expropiado por el franquismo.

12 La Voz (1920-1939) fue un periódico vespertino madrileño editado por la misma empresa que el matutino El Sol y dirigido por Enrique Fajardo, alias Fabián Vidal. A pesar de ello, la Voz llegó a superar en ventas a El Sol, siendo un periódico sumamente popular que llegó a competir con diarios líderes como $\mathrm{ABC}$ o el Heraldo de Madrid. Fue un diario que nació durante la monarquía, pero una vez Ilegada la Segunda República, su ideología estuvo ligada a Manuel Azaña y a Izquierda Republicana (Checa Godoy, 1989).

13 El Luchador (1913-1938) fue un periódico republicano que se editó en Alicante. Apoyó a la figura de Manuel Azaña de Izquierda Republicana.

14 El socialista es el órgano oficial del PSOE. Fue fundado por Pablo Iglesias en 1886.

15 Mundo Obrero es el órgano oficial del PCE desde 1930. Su sede se encuentra en Madrid. Durante algunos períodos de La República fue clausurado por lo que el PCE suplió esta falta con la edición de otros periódicos.

16 Ondas fue una revista madrileña especializada en radiodifusión que se editó entre 1925 y 1935. Fue órgano oficial de Unión Radio S.A.

17 Orbe fue una publicación madrileña que se editó entre 1932 y 1933 bajo el subtítulo «revista de telecomunicación". Fue el órgano del Sindicato Nacional de Telégrafos. Estuvo dirigida por Virgilio Soria y había sido creada para impulsar el telégrafo, el teléfono y la radiodifusión en España.

18 En cuanto al tema de la radiodifusión, el gobierno del Primer Bienio no rompió drásticamente con las políticas comunicacionales del régimen anterior. Aunque desarticuló la Junta Técnica e Inspectora que había regulado a las radios durante la dictadura, no se lograron cambios sustanciales. $\rightarrow$ 
en España también se podría lograr una modernización a través del desarrollo de la radiodifusión. Se creía que una de las formas de llevar la cultura a los hogares españoles era transmitiendo conciertos musicales, novedades artísticas u obras literarias. ${ }^{19}$ También se afirmaba que la uRss había comprendido la importancia de la radiofonía como método más eficaz para llegar y educar al pueblo, mientras en España la radio se encontraba en el mismo estado que en sus orígenes. ${ }^{20}$

En contraste, la otra visión entendió a Radio Moscú como parte del avance de la influencia soviética en España, tanto en un plano material como en uno simbólico. Aquellos hombres de negocios que veían con interés a la radiodifusión manifestaron su preocupación cuando una de las longitudes de onda reservadas al grupo radiofónico Unión Radio por los tratados internacionales de radiodifusión, fue ocupada por una estación de la URSs ocasionando interferencias. ${ }^{21} \mathrm{~A}$ su vez, nacionalistas y conservadores se inquietaban ante el hecho de que Radio Moscú pudiese contaminar su modelo de valores y creencias con ideas comunistas. Publicaciones carlistas como Pensamiento Alavés o El Siglo Futuro afirmaban que el Estado Soviético utilizaba la radiodifusión para desarrollar un sistema que les permitiese extender a España el espíritu de la fe comunista ${ }^{22}$ que pondría en peligro los valores ligados a la familia

A pesar de haberse creado nuevas estaciones de radio, el Ministerio de Comunicaciones republicano no logró el desarrollo de un sistema de radiodifusión con una cobertura que llegase a todo el país (Montoro Bermejo, 2005). Por todo esto durante la Segunda República convivieron dos tipos de radio: las ocho primeras estaciones creadas durante la dictadura reguladas por el Reglamento de Radiodifusión de 1924 y las nuevas cincuenta y nueve que se formaron entre 1933 y 1935 (Montoro Bermejo, 2005). La Ley de Radiodifusión (1934) tampoco llegó a tener consecuencias significativas y mantuvo el criterio de monopolio estatal del espectro radiofónico donde se admitía tanto la gestión privada como estatal de las emisoras que habían funcionado de esa manera desde los años primorriveristas. Así, este sistema continuó favoreciendo y dependiendo de las inversiones de los privados que habían sostenido la radiodifusión desde un punto de vista empresarial. Sin embargo, el incentivo empresarial no era suficiente para desarrollar a gran escala la radiodifusión. Los impuestos, las limitaciones en propaganda y publicidad, y la escasez de aparatos receptores, actuaron como barreras para la rentabilización del negocio.

19 "La 'radio' como medio eficaz de instrucción en Rusia” (29 de agosto de 1932) en La Voz (Madrid): Año XIII N³.642, p.06.

20 "La TSH en el país de los Soviets" (29 de julio de 1932) en Heraldo de Madrid: Año XLII N 14.506, p.07.

21 "La radiodifusión en España" (13 de enero de 1933) en La Libertad, p.08.

22 "Propaganda Soviética por Radio» (13 de marzo de 1935) en Pensamiento alavés, p.08. 
tradicional. ${ }^{23}$ A su vez, el partido conservador Acció Popular Catalana (APC) denunciaba en su órgano oficial Catalunya Social que la emisora de Moscú se dedicaba a hacer una propaganda contraria a las bases de la civilización. ${ }^{24}$

Aunque en este primer período la organización de las producciones de la emisora era incipiente, el hecho de que ambas posturas en torno a Radio Moscú hayan aparecido en las páginas de publicaciones ampliamente difundidas, colaboró en construirla como una emisora de referencia.

\section{Configuración de una agenda cultural}

Desde los orígenes de la radiodifusión durante la dictadura de Primo de Rivera, los españoles venían familiarizándose con una radio elaborada por productoras privadas destinada a un público general. En ella, los debates políticos estaban ausentes y sus principales usos estaban ligados a promover el entretenimiento y la difusión cultural, y en segunda instancia difundir informaciones reproducidas de las noticias de la prensa (Montoro Bermejo, 2005). De modo que el impacto de las emisiones de Radio Moscú estuvo ligado más bien a los contenidos culturales que eran transmitidos con regularidad. Así, las transmisiones moscovitas podían ser fácilmente asimiladas por una audiencia acostumbrada a una programación más arraigada a este tipo de programas. De esta manera, es posible observar como la emisora adoptó una continuidad de la lógica radiodifusora de la España del período estudiado.

Aunque se trató de la promoción de un uso similar, la agenda temática de Radio Moscú no trataba los mismos contenidos. La grilla de programación publicada en periódicos y revistas, revela que la emisora transmitió principalmente informaciones destinadas a propagar una imagen favorable del país de los soviets. Desde el éter, pretendió participar de los debates que circulaban en torno a la URSs para promover una percepción positiva del Estado soviético. Los programas de Radio Moscú del período trataban sobre temas relacionados a los modos de vida soviéticos, la historia de la URss, al seguimiento de las actividades deportivas, a la difusión de obras literarias, de su arte dramático radiofónico y de conciertos musicales desde el Gran Teatro de Moscú. ${ }^{25}$ También había emisiones especiales

23 "Mesa Revuelta" (14 de marzo de 1935) en El Siglo Futuro: Año XXVIII No 8.471, p.02.

24 "El peligro del Partido Comunista en nuestra casa (28 de septiembre de 1935) en Catalunya Social: Año XIV N 730, p.01.

25 Ver: "La radio en Rusia" (29 de octubre de 1932) en Ondas, p.23; «Últimas notas de la radio rusa" (24 de diciembre de 1932) en Ondas (Madrid): Año VIII N³90, p.24. 
dedicadas a los niños, a los jóvenes y a las mujeres. Según una nota publicada en la revista Ondas en 1932, en un total de cien horas de programación, Radio Moscú dedicaba cincuenta y tres a la música, diez a la instrucción y a la propaganda agrícola y técnica, siete a la propaganda política, siete a la literatura y el teatro, siete a los niños, seis a las lenguas extranjeras, siete a las informaciones y tres a la cultura física. ${ }^{26}$

Potencialmente la emisora podía ser de interés para varios segmentos de la población. Muchos sectores de clase media y alta con amplios tiempos de ocio para conocer otras culturas a través del éter encontraron un atractivo en la onda corta. ${ }^{27}$ En las columnas del periódico la Veu de Cataluny ${ }^{28}$ se comentaba que practicar la escucha de la onda corta era una «maravilla» que permitía escuchar estaciones lejanas como las americanas o hasta la de Moscú. ${ }^{29}$ En las notas publicadas por $E l$
Diluvio $^{30}$ también se señalaba que cada vez más radioaficionados madrileños dedicaban esfuerzos para escuchar la emisora soviética. ${ }^{31}$

Sin embargo, aún desde una programación cultural puede verse el trasfondo político al observarse una intención por llegar a un público interpelado por su nacionalidad y clase social. Así la emisora se dirigió a los trabajadores españoles en su propio idioma. Para ello se realizaron programas especiales dedicados a los distintos sectores del proletariado y del campesinado. ${ }^{32}$ También en reiteradas ocasiones, se invitó a tomar la palabra del micrófono de Moscú a obreros de diferentes rubros y ciudades de España. Radio Moscú se dirigía todas las noches a las masas obreras y no a los hogares individuales.

Para 1936, esto comenzó a coincidir con una experiencia de escucha que se venía gestando. A pesar del atraso de

26 "La radio en Rusia" (29 de octubre de 1932) en Ondas, p.23.

27 Ver: "Escuche extracorta” (17 de marzo de 1935) en La Veu de Catalunya: Año XLII N 12.089, p.04; "Propaganda comunista por radio" (02 de diciembre de 1933) en EI Diluvio: Año LXXVI N² 287, p.16.

28 Veu de Catalunya (1899-1937) fue un diario catalán con sede en Barcelona. Fue un periódico del partido Liga Catalana que promulgó en sus páginas una ideología catalanista y regionalista. Los contenidos de la Veu de Catalunya eran amplios. Allí se publicaron desde notas políticas hasta críticas literarias.

29 "Escuche extracorta" (17 de marzo de 1935) en La Veu de Catalunya: Año XLII N 12.089, p.04.

30 El Diluvio (1879-1939), fue un periódico fundado por Manuel de Lasarte que se editaba en castellano en Barcelona. Fue un periódico de gran tirada que nació como continuidad de El Telégrafo, y que durante la Segunda República y la Guerra Civil mantuvo una posición republicana.

31 "Propaganda comunista por radio" (02 de diciembre de 1933) en El Diluvio: Año LXXVI N 287, p.16.

32 "Estado actual de la radiodifusión en Rusia» (06 de noviembre de 1932) en Blanco y Negro, p.189. 
la radiodifusión respecto a otros países, la popularización de esta actividad fue creciendo notablemente durante los años treinta. Las clases trabajadoras en su mayoría analfabetas que no podían adquirir un receptor ni pagar sus impuestos, se la rebuscaban para poder escuchar la radio en sus tiempos libres desde los aparatos receptores instalados en centros públicos tanto culturales como de recreo, en locales partidarios o sindicales y hasta en un gran número de bares (Montoro Bermejo, 2005).

\section{Proceso interrumpido de profundización de la politización de las emisiones}

Aunque las emisiones de Moscú se caracterizaron sobre todo por una predominancia cultural, las transmisiones no fueron homogéneas durante los años abordados. Pudo observarse un proceso interrumpido de profundización de la politización de las emisiones donde la actividad política se intensificó. Fueron circunstancias donde la radio moscovita acompañó el aumento del conflicto político. La propia dinámica de la situación hizo que la emisora tuviese que practicar ciertos reacomodamientos en sus formas de intervención. Este subperíodo tuvo lugar en diciembre de 1933, octubre de I934 y enero-febrero de 1936.
La primera de estas emisiones ocurrió en las vísperas de la segunda vuelta de las elecciones generales de 1933. La noche anterior a los comicios, Radio Moscú se alejó de su programación habitual para darle la palabra a una delegación de trabajadores españoles. La mayoría de ellos eran afiliados a la Unión General de Trabajadores (UGT) que durante la transmisión recalcaron en reiteradas oportunidades que eso no les impedía tener una independencia política. ${ }^{33}$ Durante la emisión elogiaron al régimen soviético, vitorearon la revolución e incitaron a la rebelión en España.

Se cree que este acontecimiento fue una actuación organizada y planeada que se diferenció de las emisiones regulares. En un contexto electoral que habilitaba un cada vez más probable triunfo de las derechas agrupadas en la Confederación Española de Derechas Autónomas (CEDA), producto de la ruptura de la alianza republicano-socialista que había hegemonizado el primer bienio, en la emisión se percibe una intencionalidad de abrir un diálogo donde se buscaba interpelar a una base social amplia vinculada al socialismo. Aunque el PCE había presentado una lista propia en los comicios, puede verse que Radio Moscú no buscó dialogar únicamente con los adeptos al comunismo. Más bien es posible observar 
en esta acción una primera aplicación de las políticas internacionales de la IC destinadas a formar alianzas amplias ante un eventual avance fascista en España. Estos lineamientos se plasmaron en las sesiones del xirı Plenario del Comité Ejecutivo de la Komintern celebrado a fines de ese año, en el cual se habló de la posibilidad de establecer un acuerdo con el Partido Socialista Español (pSOE) frente al peligro del avance del fascismo (Hernández Sánchez, 20I7:87)

Otro reacomodamiento de las actuaciones de Radio Moscú que traza una continuidad en el subperíodo abordado ocurrió durante la Revolución de 1934 cuando luego de que el Presidente del Consejo de Ministros Alejandro Lerroux decidiese incluir en su gabinete a tres ministros de la CEDA, estallaron una serie de levantamientos que tuvieron su epicentro en Asturias. ${ }^{34}$ Durante esta insurrección, el gobierno de Lerroux monopolizó las informaciones prohibiendo cualquier tipo de actividad política por radio al declarar el «Estado de guerra». Esta resolución no hacía otra cosa que reafirmar el "Estado de alarma» que se encontraba vigente desde las huelgas de 1933 posteriores a los comicios. A su vez, el Gobierno complementó estas acciones con la clausura de los periódicos y la utilización de las radios para comunicarse con la ciudadanía (Montoro Bermejo, 2005). En este contexto de fuerte censura a los medios de comunicación nacionales, Radio Moscú practicó nuevamente un cambio de dirección. Desde el inicio de la insurrección, la emisora de Moscú comentó los sucesos y brindó información sobre los frentes de batalla. ${ }^{35}$ Para muchos comunistas de los que formaron parte de estos levantamientos fue significativo que la URss apoyase la insurrección. En sus memorias Luis Galán (1988), futuro periodista de Radio España Independiente (REI) que transmitió desde Moscú durante el franquismo, relata que durante el movimiento de 1934 intentó sintonizar la radio soviética ya que para

34 Luego de la victoria de la CEDA en las elecciones de 1933 hubo revueltas en toda España para evitar que ingresen al gobierno los partidos de derecha. Finalmente, Alejandro Lerroux del Partido Republicano Radical (PRR) pactó con la coalición y se posicionó como Presidente del Consejo de Ministros. Para octubre de 1934, este temor comenzó a hacerse realidad. El Presidente del Consejo de Ministros tomó la decisión de incluir en su gabinete a tres ministros de la CEDA en agricultura, justicia y trabajo. Nuevamente estallaron las movilizaciones en el país. Este movimiento se conoció como la Revolución de 1934 y terminó con la renuncia de Lerroux. La Revolución puso de manifiesto un consenso entre anarquistas, socialistas y comunistas donde la estrategia insurreccional era válida. Se creía que era la única forma posible de impedir que un ascenso de las derechas al gobierno pudiese poner en jaque la consolidación de la Segunda República.

35 Santander, F. (07 de noviembre de 1934) "España y la prensa extranjera” en ABC (Madrid), p.04. 
él tenía una resonancia legendaria como portadora de las ideas de la Revolución de octubre de 1917.

El último de los momentos de profundización de la politización de las emisiones tuvo lugar durante la campaña electoral de 1936 donde la crisis política y social había derivado en el enfrentamiento polarizado entre la coalición del Frente Nacional Contrarrevolucionario ${ }^{36}$ y el Frente Popular. ${ }^{37}$ El restablecimiento de las garantías constitucionales para la realización de los comicios, en conjunto con un clima político que se extendió al campo mediático, permitió a Radio Moscú la aplicación de la política fren- tepopulista de la IC propugnada desde I935 a partir del cambio de estrategia del viI Congreso. ${ }^{38}$

Radio Moscú realizó emisiones apoyando abiertamente a la coalición amplia formada por socialistas, republicanos, comunistas y sindicalistas. En estos programas, los exiliados políticos de 1934 tuvieron un rol protagónico. El 26 de enero El Socialista, ${ }^{39}$ órgano de difusión del Partido Socialista Obrero Español (PSOE), anunció que los socialistas españoles refugiados en la URss hablarían a través de la Radio de Moscú. ${ }^{40}$ Ante el triunfo del Frente Popular, la revista Crónica ${ }^{41}$ afirmó que Radio Moscú le había

36 El Frente Nacional Contrarrevolucionario agrupó a: la Confederación Española de Derechas Autónomas (CEDA), Renovación Española (RE), Comunión Tradicionalista, Partido Agrario Español (PAE), Partido Nacionalista Español (PNE);que agrupaba a la Confederación Española de Derechas Autónomas (CEDA), Renovación Española (RE), Comunión Tradicionalista, Partido Agrario Español (PAE) y al Partido Nacionalista Español (PNE).

37 El Frente Popular estuvo conformado por socialistas - Federación Nacional de Juventudes Socialistas (FNJS) y Partido Socialista Obrero Español (PSOE), que a su vez representaba a la Unión General de Trabajadores (UGT) -, republicanos - Izquierda Republicana, Unión Republicana -, comunistas - PCE - y partidos de izquierda antiestalinistas - Partido Obrero de Unificación Marxista (POUM) - y sindicalistas - Partido Sindicalista -. En Cataluña el frente fue llamado Front d 'Esquerres y se integró por Esquerra Republicana, Acció Catalana Republicana, Partit Nacionalista Republicá Catalá, Unió Socialista de Cataluña, Unió de Rabassaires, el POUM, el Partit Català Proletari y el Partido Comunista de Cataluña.

38 Este tipo de transmisiones se corresponden con las nuevas definiciones del VII Congreso de la IC realizado en 1935, donde se promovieron las políticas frente-populistas. Ante el avance de los gobiernos fascistas en Europa, el frentepopulismo buscó establecer un frente amplio de alianzas entre los partidos comunistas, fuerzas de izquierda no revolucionaria e incluso sectores de la burguesía. El PCE también formó parte de la conformación de este frente.

39 El periódico El Socialista fue y continúa siendo, desde su fundación en 1886, el órgano oficial del Partido Socialista Obrero Español (PSOE).

40 "Atención Camaradas: habla Moscú» (26 de enero de 1936) en El Socialista: Año LI N 8.043, p.05.

41 "La revista Crónica de carácter popular, se editó en Madrid entre 1929 y 1938. 
dado la noticia a los exiliados de 1934 y que ya se encontraban comenzando los preparativos para regresar a sus hogares. ${ }^{42}$

Señalamos la importancia de esta intervención porque logró ser efectiva en lo que se propuso. Al cederles el micrófono a los deportados logró ingresar su voz al interior mismo del país del cual se los había expulsado. Para esta fecha, la emisora que desde 1932 venía realizando emisiones regulares en español y practicando reacomodamientos de acuerdo a las circunstancias, ya había logrado una legitimación lo suficientemente significativa como para intervenir de alguna manera en las discusiones españolas. Sin embargo, a través de los refugiados, la emisora de Moscú lograba revalidar su intervención en el debate político de España.

\section{Reflexiones finales}

La emergencia de Radio Moscú en España (1932-1936) fue un proceso buscado e impulsado por el Estado soviético. La elaboración de políticas comunicacionales destinadas a la producción de emisiones para una audiencia hispánica fue parte de una política más general del Kremlin orientada a romper el aislamiento soviético favoreciendo la divulgación de una imagen positiva de la URss. Sin embargo, aunque la producción de programas radiofónicos desde Moscú estuvo orientada a una difusión propagandística del régimen y a intervenir sin depender de la sección local del comunismo, la forma que adquirió esta primera incursión en España se caracterizó principalmente por una agenda predominantemente cultural. Así, los programas estuvieron orientados a difundir la vida en el país de los soviets, a explicar los métodos y formas de organización de la uRss, a divulgar la historia soviética, a la lectura de obras literarias y a la propagación de conciertos musicales entre otras temáticas. La predominancia cultural de los comienzos, puede explicarse como parte de un proceso destinado a generar una legitimación en el tiempo de la emisora para producir efectos trascendentes. Se trató entonces de una política que buscó insertar a una radio aún en formación en un sistema de medio complejo ya en funcionamiento y con condiciones ya definidas de recepción. La programación cultural pudo utilizarse para ingresar en la sociedad española ya que la función social de las radios del período también estaba asociada a la difusión de la cultura y el entretenimiento. Para levantar la barrera impuesta por los demás países, la URss debió implementar una agenda que pudiese llegar a un público amplio,

42 «Cómo salieron de España, cómo llegaron a Moscú, cómo han vivido en la URSS y cómo han regresado a la Patria ciento veintiún obreros que tuvieron que expatriarse a consecuencia de los sucesos revolucionarios de Octubre de 1934" (03 de mayo de 1936) en Crónica: Año VIII N³38, p.10. 
no siempre simpatizante con las ideas del comunismo. Esta interpelación fue un hecho factible ya que la emisora se dirigía a las masas de trabajadores españoles y no a las casas particulares, coincidiendo con la experiencia de escucha colectiva desarrollada en España durante la popularización del medio. De este modo, Radio Moscú contribuyó, aún sin ser su principal objetivo, a la modernización de una por entonces exigua radiodifusión española.

La dinámica propia de la transición implicó transformaciones profundas en España. La instauración del nuevo gobierno republicano y el exilio del rey, las movilizaciones y las represiones, las huelgas revolucionarias y las intentonas golpistas, fueron hechos que también cambiaron las formas de experimentar y percibir el día a día. Estas transformaciones coyunturales implicaron modificaciones profundas que perduraron a lo largo del tiempo permitiendo a la emisora poder introducirse en la vida de la península ibérica. Sin embargo, esta situación exigió reacomodamientos y reorientaciones en las prácticas de Radio Moscú que configuraron un subperíodo interrumpido de profundización de la politización de las emisiones que permitió a la radio promover a partir de 1935 la política del frente popular, adoptada en el vir Congreso de la Internacional Comunista. Los sucesos de diciembre de I933, octubre de 1934 y enero-febrero de 1936 donde la conflictividad alcanzó su clímax y el aumento de la politización fue generalizado en todos los espacios de la vida social, permitieron a Radio Moscú activar una politización mayor. Fueron emisiones específicas destinadas a influir directamente en situaciones decisivas que no se mantuvieron de forma regular durante todos estos años. Así, pueden pensarse como un antecedente de un nuevo período de intervenciones caracterizado por el aumento de la politización de las emisiones que se abre en julio de 1936 con el estallido de la Guerra Civil.

A partir de todo lo dicho, puede concluirse que la llegada de Radio Moscú a España desde una grilla cultural fue la resultante de la articulación de un proceso social donde intervinieron el sistema de medios ya presente con formas de recepción y funciones sociales definidas, las crisis sociales y políticas republicanas, la situación interna del PCE, las políticas del Estado Soviético destinadas a romper el aislamiento, y la nueva política frentepopulista de la Komintern.

El subperíodo de profundización de la politización de las emisiones de Radio Moscú hizo evidente el sentido político de fondo de la emisora. Por lo tanto, al mirar de forma integral las formas de actuación de la emisora y los cambios de dirección, puede observarse que el contenido político aunque no fuese exteriorizado en un comienzo, siempre estuvo presente en Radio Moscú. Así queda claro que la 
lucha política también tiene su lugar al interior de la cultura (Williams, I997). Teniendo en cuenta esto, el concepto de propaganda pareciera ser demasiado acotado para explicar estos procesos. La experiencia de Radio Moscú en España pone de manifiesto que cultura y política no son espacios deslindados. Teniendo en tante frente de batalla. cuenta que la producción cultural y social se da tanto por fuera como al interior de los medios de comunicación, con este trabajo se pretendió profundizar en los fenómenos que surgen en períodos de crisis hegemónicas, donde el campo de la comunicación se alza como un impor-

Bibliografía de referencia

- ARASA, D. (2015). La batalla de las ondas en la Guerra Civil Española. Maçanet de la Selva: Editorial Gregal

- AZCÁRATE, BALAGUER, CORDÓN, FALCÓN, IBÁRRURI, SANDOVAL (1960). "Capítulo II. La República” en Historia del PCE. París: Éditions Sociales, pp. 57-113.

- BURKE, P. (1982). Enfoques oblicuos a la historia de la cultura popular. En: Bigsby, C. W. E. (comp.). Examen de la cultura popular (108-132). México: FCE.

- CERVERA, J. (1998). La radio: una arma más de la Guerra Civil en Madrid. Historia y comunicación social, (3), pp. 263-294.

- CHECA GODOY, Antonio (1989). Prensa y partidos políticos durante la II República. Universidad de Salamanca. ISBN 9788474815214.

- CRUZ, R. (1987). El partido comunista de España en la Segunda República (Vol. 506). Alianza Editorial.

- DE GUZMÁN, E. (1977). Tras las elecciones de noviembre: El estallido revolucionario de diciembre de 1933 en Tiempo de Historia: Año IV N 37, pp. 44-53.

- GALÁN, Luis (1988). Después de todo: recuerdos de un periodista de la Pirenaica. España: Anthropos - Editorial del hombre. - GARCíA DELGADO, J. y JIMÉNEZ, J.P. (2003) La Economía: Capítulo 1. El Reinado de Alfonso XIII. Un paso hacia la modernización bajo el signo del nacionalismo económico. La España del siglo XX. Marcial Pons Historia, pp.349 -401.

- GLAZOV, А. А. (2017). Роль Коммунистического Интернационала 
в системе советского радиовещания на зарубежные страны (1935-1943 гг.)[El papel de la Internacional Comunista en el sistema de radiodifusión soviética a países extranjeros (1935-1943)] (Tesis). Universidad de la Amistad de los Pueblos de Rusia, Moscú. - LACEY, K. (2002). Radio in the great depression: promotional culture, public

- HERNÁNDEZ SÁNCHEZ (2017). El Partido Comunista de España durante la Segunda República, en Bulletin d'Histoire Contemporaine de l'Espagne, $N^{\circ}$ 51, Francia: Presses Universitaires de Provence, pp.85-100.

- INTERNACIONAL COMUNISTA [IC] (1928). "La lucha por la dictadura mundial del proletariado y los tipos fundamentales de revolución" en VI Congreso de la Internacional Comunista. ¡Adelante!: Anderlecht-Bruselas, pp. 52-55.

- JULIÁ, S. (2003). Política y Sociedad. La España del siglo XX. Marcial Pons Historia, pp. 14-330.

- KÓSICHEV, L (2012). La Voz de Rusia [Programa de Radio]. Moscú: ВГТРК.

- LENIN, V.I. (1902). Plan de un periódico político destinado a toda Rusia, en ¿Qué hacer? Bs.As.: Polémica, 1974.

- MINTZ, F. (1977). La autogestión en la España revolucionaria. Madrid: La Piqueta.

- MONTES FERNÁNDEZ, F. J. (2012). Una peculiaridad en la radiodifusión española: las estaciones comarcales. Anuario Jurídico y Económico Escurialense, (45), 711-736.

- MONTORO BERMEJO, I. (2005). Capítulo 4: La radio en el tránsito de la monarquía a la república y la censura republicana (1930-1939). Libertad de Expresión e Intervención Estatal en la Radiodifusión Española de la Primera Mitad del Siglo XX. [Tesis]. Murcia: Universidad de Murcia, pp. 151-220.

- NAVARRO, A. R. (2018) Entre la legalidad y la insurrección" en Aunque nos espere el dolor y la muerte: Historia del movimiento libertario en Almería (Vol. 28). Universidad Almería.

- PIZARROSO QUINTERO, A. (2001). Intervención extranjera y propaganda. La propaganda exterior de las dos Españas. Historia y Comunicación Social. N 6, 63-96. ISSN: 1137-0734 
- PEINADO MIGUEL, F. (1998) La radiodifusión sonora en España: evolución jurídica en Revista General de Información y Documentación, Vol. $8 \mathrm{~N}^{\circ}$ 2. Madrid: Facultad de Ciencias de la Información Universidad Complutense. ISSN 1132-1873. Pp.173-192. - PÉREZ VARELA, F. (2015). "Los inicios la radio en Europa (1921-1930)". Razón y Palabra, 90. Recuperado el 20 de junio de 2019, de: http://razonypalabra.org.mx/N/N90/Varia/37_ Perez_V90.pdf.

· SPIGEL, L. (1992) Raymond Williams y la televisión. Introducción a la edición de Televisión, Tecnología y Forma cultural (Raymond Williams, Television: Technology and Cultural Form, Hanover and London, Wesleyan University Press, 1992). Traducción de Analía Hoban y Diego Balboa. En: ReHiMe. Cuadernos de la Red de historia de los medios, $N^{\circ} 2$. Buenos Aires, Prometeo, 2012. ISSN 1853-8320. pp. 14-49.

• VÁZQUEZ LIÑÁN, Miguel (2003). "Capítulo 5: La Radio". Propaganda y política de la Unión Soviética en la Guerra Civil Española (1936-1939). [Tesis]. Madrid: Universidad Complutense, pp. $197-205$.

- WILLIAMS, R. (1958). La cultura es algo ordinario. Historia y cultura común. Madrid: Los Libros de la Catarata, 2008.

- WILLIAMS, R. (1977) Marxismo y Literatura. Buenos Aires: Las Cuarenta, 2009. 